\title{
Prevalence of Apical Periodontitis in Type 2 Diabetic Patients in Northern Indians: An Original Research
}

\author{
Dr. Konark ${ }^{\star, \dagger}, 1$, Dr. Anju Singh ${ }^{2}$ \\ ${ }^{1}$ Lecturer, Department of Conservative $\mathcal{G}$ Endodontics, Patna Dental College $\mathcal{E}$ Hospital Patna \\ 2. Assistant Professor, Dentistry Nalanda Medical College $E_{3}$ Hospital Patna
}

DDOI: https://doi.org/10.15520/jcmro.v2i11.232

Accepted 14-11-2019; Received 20-10-2019; Publish Online 15-11-2019

\author{
Reviewed By: \\ Dr. K. Daniel \\ Department: \\ Reviewer/CMRO
}

\begin{abstract}
Aim: To study the Prevalence of Apical Periodontitis in Type 2 Diabetic Patients Methodology: Total of 112 controlled type 2 diabetic patients were selected for the study. The age of patients was 50 to 65 years. Out of 112 patients, 60 patients were males and 52 patients were female. All patients underwent a full-mouth radiographic survey incorporating 14 periapical radiographs. Periapical areas including periapical bone, periodontal ligament space and lamina dura, were examined in all individuals excluding $3^{\text {rd }}$ molar.

Results: Out of 112 type 2 diabetic patients 87 patients were diagnosed with apical periodontitis. Out of 2800 examined teeth, 188 teeth were diagnosed with apical periodontitis and 2612 teeth were found to be not associated with apical periodontitis. Out of 2800 examined teeth, $6.71 \%$ teeth were found to be associted with apical periodontitis.
\end{abstract}

Conclusion: Prevalence of apical periodontitis in type 2 diabetic patients is $77.68 \%$.

Key words: Apical periodontitis-Type 2 diabetes mellitus

\section{INTRODUCTION:}

Diabetes mellitus is a complex metabolic disorder, a syndrome characterized by abnormalities in carbohydrate, lipid $\&$ protein metabolism that result either from profound or absolute deficiency of insulin or from target tissue resistance to its cellular metabolic effects [1]. The prevalence of diabetes is rapidly rising all over the globe at alarming rate. Type 2 diabetes mellitus is the commonest form of diabetes $\&$ its prevalence is $2.4 \%$ in rural population \& $11.6 \%$ in urban population. The primary driver of the epidemic of diabetes is the rapid epidemiological transition associated with changes in dietary patterns \& decreased physical activity as evident from the higher prevalence of diabetes in the urban populations. The most disturbing trend is the shift in age of onset of diabetes to a younger age in recent years [2]. Diabetes mellitus is a chronic disease with serious health consequences. Diabetics are associated with depression of natural defence against infection, increases the risk of periodontal and periradicular diseases. However the effect of diabetes on periradicular tissues which differs structurally

* Corresponding author.

$\dagger$ Email: drmkhan26@gmail.com than periodontal tissues are not discussed much [3]. The oral complication of Diabetes Mellitus are different types of infections, delayed wound healing, dryness of mouth (xerostomia) increased incidence \& severity of caries, gingival and periodontal disorders (gingivitis, periodontitis, periodontal abscess, pericoronal abscess), burning mouth syndromes, apical periodontitis, periapical abscess and frequent oral ulcers. Poorly controlled insulin dependent diabetes (PIDD) had more gingivitis \& attachment loss \& gingival recession than controlled insulin dependent diabetes (CIDD) with a mean HBAI C of $9.2 \%$ [4].

Higher incidence of attachment loss had been described among diabetics. Increased susceptibility to periodontal diseases due altered host response, subgingival microflora, collagen metabolism, vascularity [5].

\section{METHODOLOGY:}

Total of 112 controlled type 2 diabetic patients were selected for the study. Informed consent was obtained from the patients selected for the study. The age of patients was 50 to 65 years. Out of 112 patients, 60 patients were males and 52 patients were female. Informed consent was obtained 
from the patients selected for the study. Patients with other known systemic disorders were excluded from the study. Patients with excessive reduced mouth opening were excluded from the study. Patients with maxillofacial swelling were excluded from the study. Examination of the oral cavity was performed under good illumination using gloves, probe, and mirror according to Kerr, Ash, Millard and WHO guidelines. Examination of the oral cavity was performed under good illumination using gloves, probe, and mirror according to Kerr, Ash, Millard and WHO guidelines. All patients underwent a full-mouth radiographic survey incorporating 14 periapical radiographs. Periapical areas including periapical bone, periodontal ligament space and lamina dura, were examined in all individuals excluding $3^{\text {rd }}$ molar. Widening of periodontal ligament space and thickening of lamina dura was analysed for the radiographical diagnosis of apical periodontitis.

\section{STATISTICAL ANALYSIS:}

The data was compiled using Microsoft excel sheet (Windows 2010) and analysed using SPSS software (version 17.0) All results were compared using percentage.

\section{RESULTS:}

Total of 112 known type 2 Diabetic Patients were selected for the study. Out of 112 type 2 diabetic patients, 60 were male and 52 were female.

Table 1. Gender Wise Distribution of Type 2 Diabetic Patients

\begin{tabular}{ll}
\hline Total & 112 \\
Male & 60 \\
Female & 52 \\
\hline
\end{tabular}

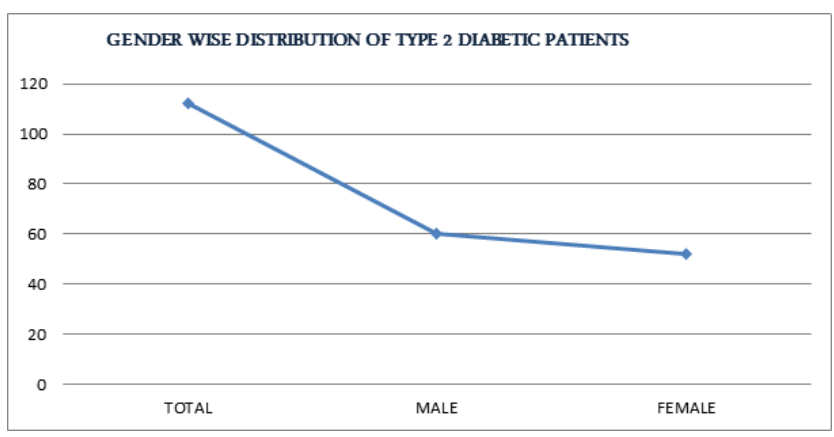

GraphNo. 1:- Gender Wise Distribution of Type 2 Diabetic Patients

Out of 112 known type 2 diabetic patients $53.57 \%$ were male and $46.43 \%$ were female.

Out of 112 type 2 diabetic patients 87 patients were diagnosed with apical periodontitis.
Table 2. Percentage of Gender Wise Distribution Type 2 Diabetic Patients

\begin{tabular}{ll}
\hline TOTAL & $100 \%$ \\
MALE & $53.57 \%$ \\
FEMALE & $46.43 \%$ \\
\hline
\end{tabular}

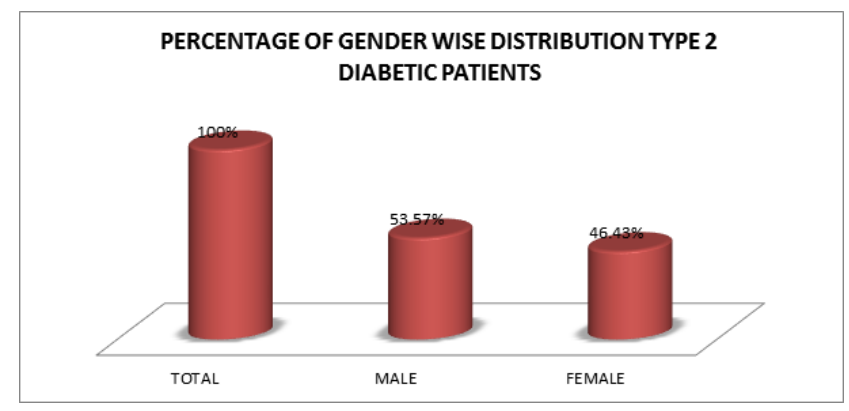

GraphNo. 2:- Percentage of Gender Wise Distribution Type 2 Diabetic Patients

Table 3. Prevalence of Apical Periodontitis in Type 2 Diabetic Patients

\begin{tabular}{ll}
\hline PATIENT WITH APICAL PERIODONTITIS & 87 \\
PATIENT WITHOUT APICAL PERIODONTITIS & 25 \\
TOTAL NO. OF PATIENTS & 112 \\
\hline
\end{tabular}

PREVALENCE OF APICAL PERIODONITTIS IN TYPE 2 DIABETIC PATIENTS

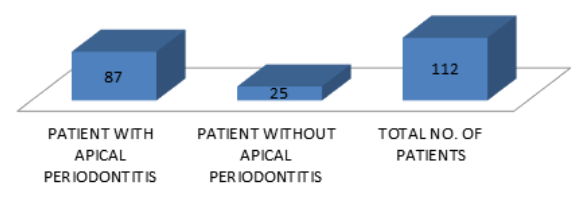

GraphNo. 3:- Prevalence of Apical Periodontitis in Type 2 Diabetic Patients

Table 4. Percentage of Prevalence of Apical Periodontitis in Type 2 Diabetic Patients

\begin{tabular}{lc}
\hline PATIENT WITH APICAL PERIODONTITIS & $77.68 \%$ \\
PATIENT WITHOUT APICAL & $22.32 \%$ \\
PERIODONTITIS & \\
TOTAL NO. OF PATIENTS & $100 \%$ \\
\hline
\end{tabular}

Out of 112 type 2 diabetic patients, $77.68 \%$ patients were diagnosed with apical periodontitis.

Table 5. Prevalence of Apical Periodontitis in Total Number of Teeth

\begin{tabular}{ll}
\hline TOTAL NUMBER OF TEETH EXAMINED & 2800 \\
TEETH WITH APICAL PERIODONTITIS & 188 \\
TEETH WITHOUT APICAL PERIODONTITIS & 2612 \\
\hline
\end{tabular}

Out of 2800 examined teeth, 188 teeth were diagnosed with apical periodontitis and 2612 teeth were found to be not associated with apical periodontitis. 


\section{Prevalence of Apical Periodontitis in Type 2 Diabetic Patients in Northern Indians: An Original Research

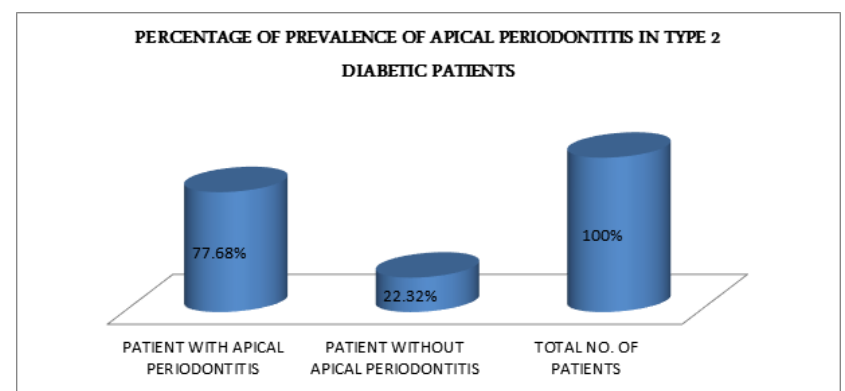

GraphNo. 4:- Percentage of Prevalence of Apical Pe-riodontitis in Type 2 DiabeticPatients

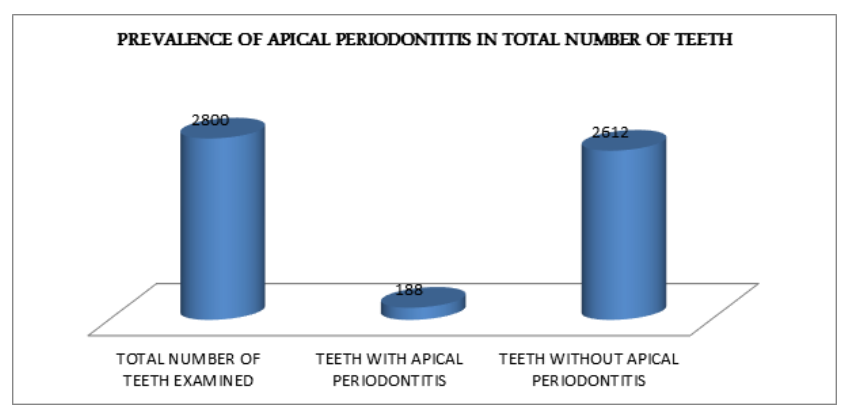

GraphNo. 5:- Prevalence of Apical Periodontitis in Total Number of Teeth

Table 6. Percentageof Prevalence of Apical Periodontitis in To-tal Number of Teeth

$\begin{array}{ll}\text { TOTAL NUMBER OF TEETH EXAMINED } & 100 \% \\ \text { TEETH WITH APICAL PERIODONTITIS } & 6.71 \% \\ \text { TEETH WITHOUT APICAL PERIODONTITIS } & 93.29 \%\end{array}$

Out of 2800 examined teeth, $6.71 \%$ teeth were found to be associted with apical periodontitis

PERCENTAGE OF PREVALENCE OF APICAL PERIODONTITIS IN TOTAL NUMBER OF TEETH

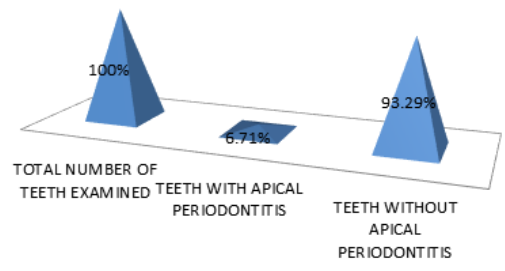

GraphNo. 6:- Percentage of Prevalence of Apical Pe-riodontitis in Total Number ofTeeth

5 DISCUSSION:

The patients included in this study were controlled type 2 diabetic patients. General clinical features of diabetes mellitus are polyurea, polydipsia. The most common complications of diabetes mellitus are neuropathy, retinopathy and nephropathy. In this study the prevalence of apical periodontitis in controlled type 2 diabetic patients were found to be $77.68 \%$ and in the total examined teeth was found to be $6.71 \%$. Another study showed that total number of teeth with AP (Apical periodontitis) was 86 (5.2\%) of the total [6]. This study is in line with our study. Another study showed that the frequency of teeth with AP in other studies varies from $0.6 \%$ [7]. This study is not in line with our study. Another study showed that the prevalence of apical periodontitis is $9.8 \%$ [8].

\section{CONCLUSTON:}

Previous studies reported that there is high prevalence of periapical pathologies including apical periodontitis in type 2 diabetic patients. In our study the prevalence of apical periodontitis is also high. The previous studies and my study strongly support the concept that diabetes acts as a risk factor for Apical Periodontitis, increasing its prevalence and may affect the outcome of the root canal treatment.

\section{Acknowledgement}

Authors acknowledge the immense help received from the scholars whose articles are cited and included in reference of this manuscript. The authors are grateful to authors / editors / publishers of all those articles, journal and books from where the literature for this article has been reviewed and discussed.

\section{REFERENCES}

[1] Vemilllo AT. Dental considerations for treatment of patients with diabetes. JADA. 2003;134:24-33.

[2] Mohan V, Sandeep S, Deepa R, Shah B, Varghese C. Epidemiology of type 2 Diabetes: Indian scenario. Indian J Med Res. 2007;125:217-247.

[3] Nayak S, Kotigadde H, Shetty K, RM. ENDODONTOLOGY;

[4] Seppala B, Seppala M, Ainamo J. A longitudinal study on insulin dependent diabetes mellitus \& periodontal disease. J Clin Periodontal. 1993;20:161-166.

[5] Segura-Egea JJ, Jimenez-Pinzon A, Rios-Santos JV, Velascoortega E, Cisneros-Cabello R, Poyata-Ferrara M. High prevalence of apical periodontitis among type 2 diabetic patients. Int Endod J. 2005;38:564-573.

[6] Segura-Egea JJ, nez Pinzo' n AJ, os Santos JVR, VelascoOrtega E, Cisneros-Cabello R, Poyato-Ferrera M. High prevalence of apical periodontitis amongst type 2 diabetic patients. International Endodontic Journal. 2005;38:564-569.

[7] Eriksen HM, Berset GP, Hansen BF, Bjertness E. Changes in endodontic status 1973-93 among 35-year-olds in Oslo. International Endodontic Journal. 1995;28:129-161.

[8] A radiographic survey of periapical conditions in elderly people in a Swedish country population. Endodontics and Dental Traumatology. 1986;(2):103-111. 